\title{
Facing up to gender inequality in ophthalmology and vision science
}

\author{
Helen Khan ${ }^{1} \cdot$ Mariya Moosajee ${ }^{1,2}$
}

Received: 26 April 2018 / Accepted: 2 May 2018 / Published online: 15 June 2018

(c) The Royal College of Ophthalmologists 2018

The recent surge of activity in women's rights and equality in the workplace has been paralleled with a movement of women working in vision-related sciences and healthcare. It still remains that, globally, women face a gender wage gap, earning the equivalent of only $77 \%$ of their male counterparts. Women held just $12 \%$ of the world's positions on boards of directors in 2015 [1].

According to statistics provided in The Lancet editorial: 'A year of reckoning for women in science', women across Science, Technology, Engineering, Maths and Medicine (STEMM) have been short-changed in terms of promotions, higher pay and recognition awards [2]. Women are not necessarily paid less for doing the same jobs as men, but are more likely to be in lower-paid jobs. Media and professional opinion is divided on why this is so; some believe it is due to traditional beliefs, preconceptions or religion. It is an emotive subject where conclusions, whether right or wrong, are drawn. However, it is clear that women are more likely to be their children's main carers and are more likely to have to take a step back from their careers for a certain amount of time. In eight countries polled by The Economist and YouGov in 2017, 44-75\% of women with children living at home said they had started working fewer hours or switched to a less-demanding job, since becoming mothers. Only $13-37 \%$ of fathers said they had done the same [3].

Despite these gloomy figures, attitudes, beliefs and thinking relating to gender are transforming due to leaders and pioneers being determined to change the existing practice. Recent global media coverage has highlighted an evolution in the workplace, leading to gender imbalances not

Helen Khan

helen.khan@ucl.ac.uk

1 National Institute for Health Research (NIHR) Biomedical Research Centre at Moorfields Eye Hospital NHS Foundation Trust and UCL Institute of Ophthalmology, London, UK

2 Department of Ophthalmology, Great Ormond Street Hospital for Children NHS Foundation Trust, London, UK being accepted or tolerated. Momentum is being generated in order to truly reconstruct thinking, habits and tradition.

\section{The women's movement in ophthalmology and vision science}

Ophthalmology and vision science professions have not been immune to the gender inequality seen in STEMM and other related industries. In 2016, the Royal College of Ophthalmologists reported that $74 \%$ of consultants in the UK were male [4]. Traditionally, men have gained the higher-level positions; for example, in the US, 78\% comprise the full professor rank [2]. They achieve superior recognition via awards and accolades and have been more prominent on speaker panels. This is exemplified in The Ophthalmologist's 2018 Top 100 most influential people in the world of ophthalmology consisting of only 13 women, up by four since the $9 \%$ female representation in 2016 .

To oppose this historical and traditional predicament, an initiative is being pioneered by Dr Mariya Moosajee, Prof Julie Daniels and Dr Maryse Bailly, who are collectively breaking new ground to ensure equality across the profession. These women recognised a need for change and took action by establishing the Women in Vision UK (WVUK) network. Initially founded to increase the number of female speakers at conferences and on expert panels, it rapidly developed into a network of support, mentorship, collaboration and leadership to enhance the profiles and careers of women.

This initiative had clearly been long-awaited, and, in a short space of time, the growing network already consists of over 250 members across the UK. Despite WVUK being in a relatively early stage, plans are already in progress to empower and engage members. These include the coordination of a strong multidisciplinary board, provision of travel grants and childcare allowances for attendance at conferences, training opportunities, and the establishment of mentoring programmes. As per the initial concept, a female expert engagement list has been developed alongside Fight for Sight, for use at forums ranging from schools, scientific 
meetings and advisory boards, including policy-making and grant review panels. This list will ensure that there is a more equal representation of experts and suitable candidates. The intention is that it will be accessed by both men and women keen to ensure equality.

\section{Working with Athena Swan}

Underpinning WVUK has been the Athena SWAN charter, established in 2005 to encourage and recognise commitment to advancing the careers of women in STEMM in higher education and research. In 2015, the charter was expanded to encompass the arts, humanities, social sciences, business and law, including those in professional and support roles, and for trans staff and students. Athena SWAN is now a beacon addressing gender equality more broadly, and not just barriers to progression that affect women. Dame Sally Davis developed the Athena Swan awards system of Bronze, Silver and Gold status to positively encourage men and women to apply and work towards equality.

The establishment of WVUK on the framework of Athena Swan highlights the success of the charter as a springboard for speciality change on a national and international level. It is a positive example of a united professional shift in equality, as well as having the capacity to shine a light on practice that needs to be changed.

\section{WVUK's inclusivity promise}

WVUK supports and welcomes anyone interested, associated with or working in vision. WVUK is not limited to ophthalmologists and encourages the membership of all allied healthcare professionals and researchers, from high street optometrists to academic bioinformaticians and stem cell biologists. This not only enables the group to gather insights and experiences from across the profession, but also ensures that the ethics and commitments extend to a wider and more diverse network. The inclusivity of the group is important to demonstrate its equality.

The inaugural meeting in December 2017 was a success, with high-profile women speaking out about their experiences of gender bias and volunteering to lead advancement in their own practice. The meeting became the pivotal point where pledges were made to change practice for the future. The foundation is now being laid to encourage young women to enter a profession striving for gender equality, accompanied by continued support and mentorship to retain and enhance their careers.

The group is fast becoming a prominent force, with its first international meeting held at the annual meeting for the
Association for Research in Vision and Ophthalmology (ARVO), where members joined the Women in Eye And Vision Research (WEAVR) group and the European Association for Eye and Vision Research (EVER). This presence will establish international links with other countries where similar issues are apparent. WVUK is exploring ways to demonstrate that it is a case study and example of positive change, while garnering insights from international partners and networks.

On a more local scale, splinter meetings are planned nationally to allow local networks to develop to foster future shifts in gender balance at ground level. Feedback from members so far has shown that activities and projects are starting to take shape via enthusiastic members determined to make advances in their own geographical and professional areas.

\section{The future of WVUK}

Women deserve the same opportunities as men, and they should be able to pursue a fulfilling and successful career in an area that they choose. Women and men are equally able, so it is important now to make changes and work together. By failing to address the current gender imbalance, we risk losing talent and diversity, which ultimately has a negative impact on society in terms of economy, discovery and development. The balance will not shift immediately; there is potentially a long journey ahead. However, with persistence, determination and support from all, we will achieve gender equality across ophthalmology and vision sciences.

Acknowledgements WVUK would like to thank the National Institute for Health Research (NIHR) Biomedical Research Centre at Moorfields Eye Hospital and UCL Institute of Ophthalmology and Fight for Sight for their support.

\section{Compliance with ethical standards}

Conflict of interest The authors declare that they have no conflict of interest.

\section{References}

1. Catalyst Knowledge Centre. Quick Take. Global. Statistical Overview of Women in the Workforce. 2017; http://www.catalyst.org/ knowledge/statistical-overview-women-workforce.

2. Year of reckoning for women in science. Lancet. 2018;391:513.

3. The Economist. Men, Women and Work. The Gender Pay Gap. Women still earn a lot less than men, despite decades of equal pay laws. Why? 2017. Print edition. https://www.economist.com/ international/2017/10/07/the-gender-pay-gap.

4. Royal College of Ophthalmology. Workforce census. Weblink. 2017. 